\title{
A Study of Functional Genomics for Unknown Proteins in Chlamydomonas reinhardtii
}

\author{
Manisha D. Giripunje \\ Department of Environmental \\ Science, Sevadal Mahila \\ Mahavidyalaya, Nagpur- 440015, \\ Maharashtra, India.
}

\author{
Abhay B. Fulke \\ CSIR-National Environmental \\ Engineering Research Institute, \\ Nagpur-440020, \\ Maharashtra, India.
}

\author{
Pravin U. Meshram \\ Department of Environmental \\ Science, Sevadal Mahila \\ Mahavidyalaya, Nagpur- 440015, \\ Maharashtra, India.
}

\begin{abstract}
Chlamydomonas reinhardtii is a unicellular green alga, which has been used as a reference organism for identifying proteins. Five hundred hypothetical proteins in Chlamydomonas reinhardtii have been sequenced for knowing functions of the proteins in their families. Functions of Five hundred hypothetical proteins in Chlamydomonas reinhardtii were predicted using bioinformatics web tools. The web tools like CDD-BLAST, INTERPROSCAN and PFAM were used for the prediction of functions in the proteins by searching protein databases for the presence of conserved domains. The current study was useful in better knowing the functions of hypothetical proteins in Chlamydomonas reinhardtii and the various regulatory mechanisms, which interact to yield a final output from the system.
\end{abstract}

\section{Keywords}

Chlamydomonas reinhardtii, Bioinformatics Web Tools, hypothetical proteins, Conserved Domains

\section{INTRODUCTION}

Chlamydomonas reinhardtii is the unicellular biflagellate green alga [1]. Chlamydomonas reinhardtii is known to us as model organism because of its physiological, metabolic and genetic characteristics that expresses the structure, function and regulation of the photosynthetic apparatus [2]. $C$. reinhardtii has been used for genome-wide studies of cell motility, photosynthesis [3], phototaxis, cell wall biogenesis and additional essential cellular actions. Bioinformatics analysis of Chlamydomonas has been highlighted the photosynthetic function, in which set of proteins indicated the "GreenCut" [4]. Chlamydomonas reinhardtii also develops in the dark on an organic carbon source while maintaining a functional photosynthetic apparatus. Many Chlamydomonas genes can be traced to the green plant or plant-animal common ancestor by comparative genomic analysis [5]. The Chlamydomonas nuclear genome includes seventeen linkage groups presumably corresponding to seventeen chromosomes, consistent with electron microscopy of meiotic synaptonemal complexes [6]. The Chlamydomonas genome has about uniform densities of genes, simple sequence repeats and transposable elements. Most Chlamydomonas proteins exhibit slightly more similarity to Arabidopsis than to human proteins [7]. Many hypothetical proteins in Chlamydomonas reinhardtii are not functionally annotated. The unknown proteins functions estimate with database and algorithm of bioinformatics tools. The early study of proteins functions in Chlamydomonas reinhardtii was annotated. However, the database was increased after the improvement in the gene models. Therefore, about one-forth portion of the protein coding gene models were correctly annotated [8].

The current study is an effort to know and assemble the information associated with functional annotations of unknown proteins in Chlamydomonas reinhardtii. Functions and classification of target protein in family can explore through homologous/orthologous sequence in biological sequence databases for the target sequences using computational tools like CDD-BLAST, INTERPROSCAN and PFAM $[9,10]$.

\section{METHODOLOGY}

\subsection{Sequence analysis of Chlamydomonas reinhardtii}

The original database of the genomic sequences of Chlamydomonas reinhardtii was generated by Joint Genome Institute (JGI). Kyoto Encyclopedia of Genes and Genomes (KEGG) maintained the database resource of genome. Sequences of Chlamydomonas reinhardtii hypothetical proteins were recollected from the KEGG database (http://www.genome.jp/kegg/) [11] (using the primary accession number T01039 and the entry name cre, CHLRE, 3055.)

\subsection{Genomics analysis of Chlamydomonas reinhardtii}

The workflow of genomics analysis was described and the unknown proteins from Chlamydomonas reinhardtii were screened for the use of bioinformatics tools. First, Conserved Domain Database CDD-BLAST tool search was executed for Chlamydomonas reinhardtii (http://www.ncbi.nlm.nih.gov/BLAST/) that presented as an annotation of protein domains [12, 13 and 14] NCBI-CDD is a protein annotation resource that consists of a collection of well-annotated multiple sequence alignment models for ancient domains and full-length proteins [15]. Then, search was performed by InterProScan tool, which combines protein signature recognition methods native to the InterPro member databases into one resource (http://www.ebi.ac.uk/interpro) [16]. The prediction of uncharacterized proteins was carried out by Pfam v27.0 (http://www.pfam.sanger.ac.uk/) which includes their annotations and multiple sequence alignments generated using hidden Markov models [17,18]. Unknown proteins studied with bioinformatics tools, resulted the conserved domains in hypothetical sequences. The domains in 
hypothetical sequences are useful in advanced classification of proteins into their individual family.

The present study focused on sequence genomics analysis of Chlamydomonas reinhardtii hypothetical proteins as summarized in Figure 1.

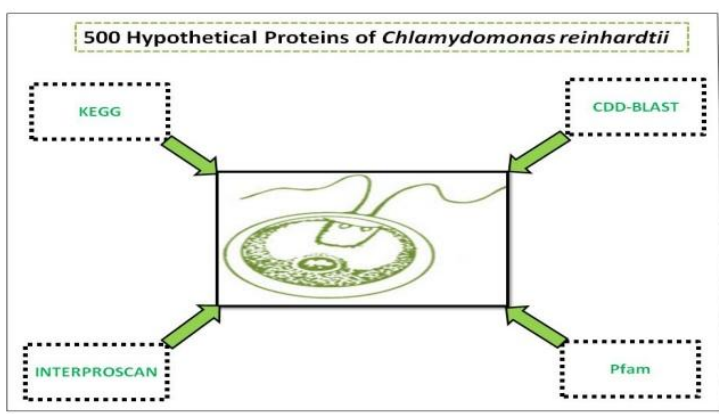

Table 1: Identified hypothetical proteins of Chlamydomonas reinhardtii using genomics.
Fig.1: Schematic diagram of hypothetical proteins of Chlamydomonas reinhardtii

\begin{tabular}{|c|c|}
\hline & 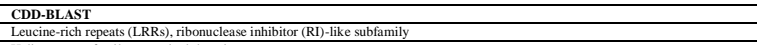 \\
\hline 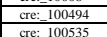 & 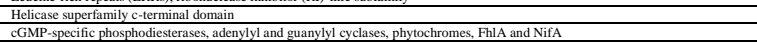 \\
\hline & 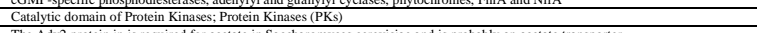 \\
\hline$\frac{c \text { cre: }}{\text { cre: }}$ & 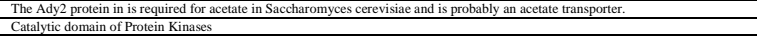 \\
\hline (178 & 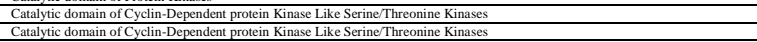 \\
\hline & 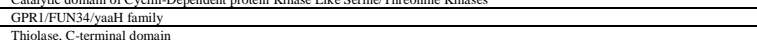 \\
\hline 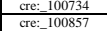 & 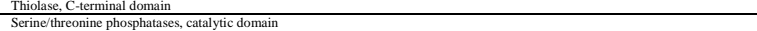 \\
\hline 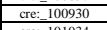 & 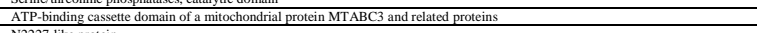 \\
\hline$\frac{\mathrm{coc}}{\mathrm{coce}}$ & 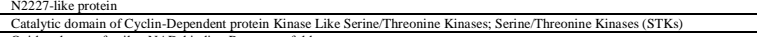 \\
\hline 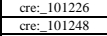 & 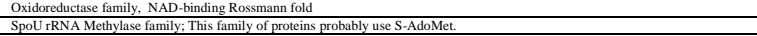 \\
\hline 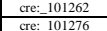 & 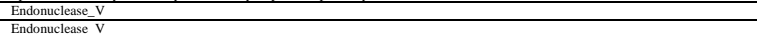 \\
\hline $\begin{array}{lll}\text { cre }: 1010285 \\
\end{array}$ & $\begin{array}{l}\text { Iron-sulfur cluster assembly yacecssory y protein } \\
\text { In }\end{array}$ \\
\hline 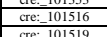 & 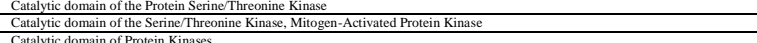 \\
\hline & 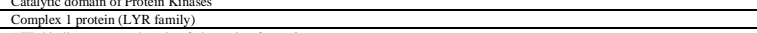 \\
\hline & $\begin{array}{l}\text { ATP-binding cassete domain of elongation factor } 3 . \\
\text { Catatlyic domina of Protein Kinases }\end{array}$ \\
\hline 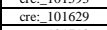 & $\begin{array}{l}\text { The Fert_NitH superfamily; cobbW C-terminal domain, Putative GTPases } \\
\text { The }\end{array}$ \\
\hline 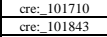 & 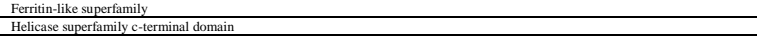 \\
\hline & Cytochrome b5-like Heme/Steroid binding domain \\
\hline $\begin{array}{lll}\text { cré: }=1010941 \\
\end{array}$ & 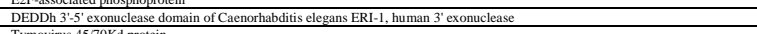 \\
\hline & 70KS dorotetin \\
\hline 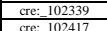 & omain \\
\hline 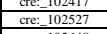 & Squalene/phytoene synthase \\
\hline 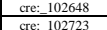 & If Cyclin-Dependent protein Kinase Like Seri \\
\hline 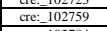 & 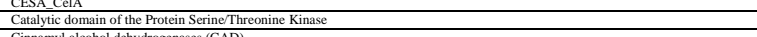 \\
\hline 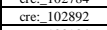 & 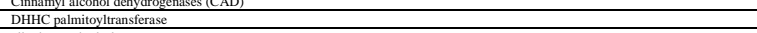 \\
\hline 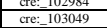 & olase \\
\hline 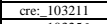 & the pleiotropic druy resistance-like (PDR) \\
\hline $\begin{array}{cccc}\text { cre:e: } 1033256 \\
\text { cre }=10335\end{array}$ & 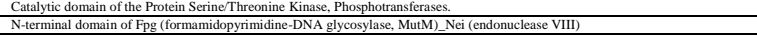 \\
\hline 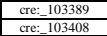 & 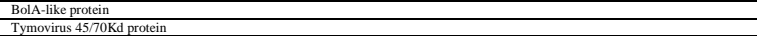 \\
\hline 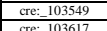 & 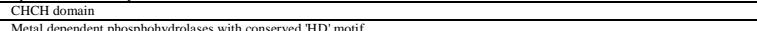 \\
\hline & 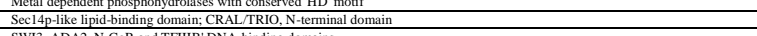 \\
\hline 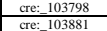 & 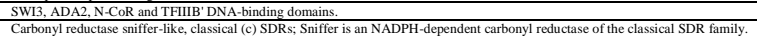 \\
\hline 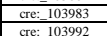 & 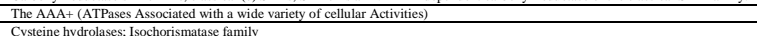 \\
\hline 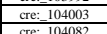 & 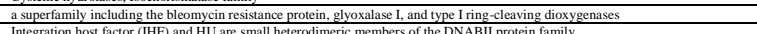 \\
\hline & 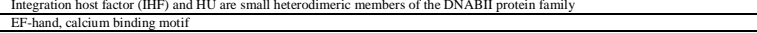 \\
\hline cre:: $=104111$ & \\
\hline cre: $=1043000$ & $10237)$ \\
\hline 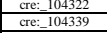 & 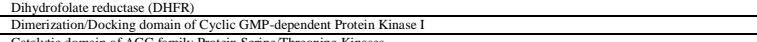 \\
\hline cre::104389 & 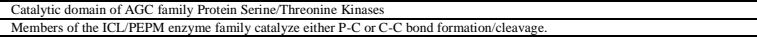 \\
\hline 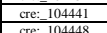 & 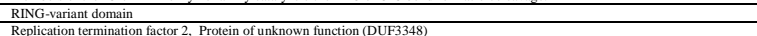 \\
\hline 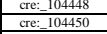 & Mechyltransterase domain \\
\hline 的: 104519 & ceally Interesting New Genec) domain \\
\hline$\frac{104832}{1.04611}$ & penanorec acci aldoalese \\
\hline 04719 & 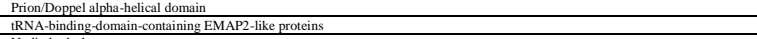 \\
\hline 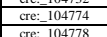 & motif in yeast cell wall integrity protein scw1 \\
\hline 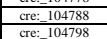 & 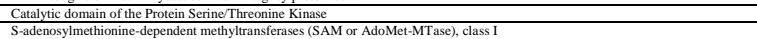 \\
\hline
\end{tabular}

\begin{tabular}{|c|c|}
\hline \begin{tabular}{|l|} 
INTERPROSCAN \\
No
\end{tabular} & \begin{tabular}{|l} 
Pram \\
Leucinc-rich repeats
\end{tabular} \\
\hline Signal-peptide & DEAD/DEAH box helicase, Helicase conserved C-terminal \\
\hline Signal-peptide & GAF domain \\
\hline \begin{tabular}{|l} 
Signal-peptide \\
No
\end{tabular} & Protein kinase domain \\
\hline \begin{tabular}{|l} 
No \\
Signal-peptide \\
\end{tabular} & $\begin{array}{l}\text { GPRI/FUN34/yaaH family } \\
\text { Protin kinsed comain }\end{array}$ \\
\hline Signal-peptide & $\begin{array}{l}\text { Protein kinase domain } \\
\text { Protein kinase domain }\end{array}$ \\
\hline & Protein kinase domain \\
\hline Signal-peptide & $\begin{array}{ll}\text { GPRI/FUN34/yaah family } \\
\end{array}$ \\
\hline $\begin{array}{l}\text { Signal-peptide } \\
\text { sgatid }\end{array}$ & $\begin{array}{l}\text { Uncharacterised protein } \\
\end{array}$ \\
\hline 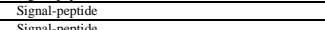 & Protein phosphatase $2 \mathrm{C}$ \\
\hline$\frac{\text { Signal-peptide }}{\text { No }}$ & $\begin{array}{ll}\text { ABC transporter } \\
\text { N2227.jik protein }\end{array}$ \\
\hline$\frac{\text { No }}{\text { No }}$ & $\frac{\text { N2227-like protein }}{\text { Protein kinase domain }}$ \\
\hline Signal-peptide & $\begin{array}{l}\text { Froteln inases domann } \\
\text { Xxidoreductase family, NAD-binding Rossmann fold }\end{array}$ \\
\hline & SpoU rRNA Methylase family \\
\hline Signal-peptide & Endonuclease \\
\hline $\begin{array}{l}\text { Signal-peptide } \\
\text { Nol }\end{array}$ & 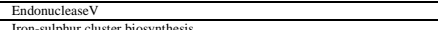 \\
\hline$\frac{\text { No }}{\text { Signal-peptide }}$ & Iron-sulphur cluster biosynthesis \\
\hline $\begin{array}{l}\text { Signal-peptice } \\
\text { Signal-peptide }\end{array}$ & $\frac{\text { Protein kinase domain }}{\text { Protein kinase domain }}$ \\
\hline & Protein kinase domain \\
\hline Signal-peptide & Complex I protein (LYR family) \\
\hline Signal-peptide & $\mathrm{ABC}$ transporter \\
\hline \begin{tabular}{|l} 
Signal-peptide \\
SGEP N1
\end{tabular} & Protein kinase domain \\
\hline 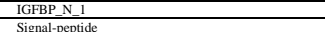 & No \\
\hline$\frac{\text { Signal-peptide }}{\text { No }}$ & Protein of unknown function \\
\hline$\frac{\mathrm{N} \text { No }}{\mathrm{No}}$ & $\begin{array}{l}\text { Helicase conserved C-terminal domain } \\
\text { Cytcochrome b5-like Heme/Steroid binding domain }\end{array}$ \\
\hline Signal-peptide & E2F-associated phosphoprotein ondung domain \\
\hline Signal-peptide & Exonuclease \\
\hline & \\
\hline IGFBP_N_I & Ankyrin repeats $(3$ copies $)$ \\
\hline & Sacl homology domain \\
\hline Signal-peptide & No \\
\hline Signal-peptide & Squalene/phyloene synthase \\
\hline Signal-peptide & $\begin{array}{l}\text { protein kinase domain } \\
\text { Pres }\end{array}$ \\
\hline Signal-peptide & Glycosyl transferase family group 2 \\
\hline No & $\begin{array}{ll}\text { Protein kinase domain } \\
\end{array}$ \\
\hline \begin{tabular}{|l} 
Signal-peptide \\
\end{tabular} & Alcohol dehydrogenase GroES-like domain; Zinc-binding dehydrogenase \\
\hline Signal-peptide & DHHC palmitoyltransferase \\
\hline $\begin{array}{l}\text { Signal-peptide } \\
\text { No }\end{array}$ & \\
\hline $\begin{array}{l}\text { No } \\
\text { IGFBP_N_1; AGOUTI_l:Transmembranc_regions } \\
\end{array}$ & 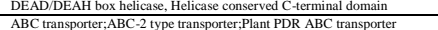 \\
\hline Signal-peptide & 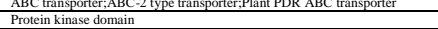 \\
\hline Signal-peptide;Transmembrane_regions & Formamidopyrimidine-DNA glycosylase N-terminal domain, $\mathrm{H} 2 \mathrm{TH}$ domain \\
\hline & BolA-like protein \\
\hline Signal-peppide;:Transmembrane__egions & No \\
\hline Signal-peptide & CHCH domain \\
\hline Signal-peptide & $35^{5}$-cyclic nucleotide phosphodiesterase \\
\hline Signal-peptide & CRALTRIO domain \\
\hline & Myb-like DNA-binding domain;Myb-like DNA-binding domain \\
\hline & \\
\hline Signal-peptide & ATPase family associated with various cellular activities (AAA) \\
\hline Signal-peptide & Isochorismatase family \\
\hline $\begin{array}{l}\text { Signal-peptide; Transmembrane_regions } \\
\text { Signal-peptide }\end{array}$ & $\begin{array}{l}\text { Glyoxalase-like domain } \\
\text { Bacterial DNA-binding protein } \\
\end{array}$ \\
\hline \begin{tabular}{|l} 
Signal-pppide \\
EGGSHELLSSignal-peptide \\
\end{tabular} & $\begin{array}{l}\text { Bacterlat INA-binding procen } \\
\text { EF-hand domain EF-hand domain pair } \\
\end{array}$ \\
\hline INTEGRIN_BETA; IGFBP_N_1 & DEAD/DEAH box helicase; Helicase conserved C-terminal domain \\
\hline \begin{tabular}{|l|} 
Signal-peptide \\
\end{tabular} & Domain of unknown function (DUF1768) \\
\hline Signal-peptide & $\begin{array}{l}\text { Protein of unknown function } \\
\end{array}$ \\
\hline $\begin{array}{ll}\text { EGGSHELL; Signal-peptide } \\
\text { Signal-pentide }\end{array}$ & $\begin{array}{ll}\text { RibD C-terminal domain } \\
\text { Yo }\end{array}$ \\
\hline $\begin{array}{l}\text { Signal-peptide } \\
\text { Singal-peptide }\end{array}$ & No \\
\hline$\frac{\text { Signal-peppide }}{\text { Signal-peptide }}$ & 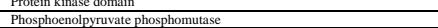 \\
\hline Signal-peptide & No \\
\hline \begin{tabular}{|l} 
Signal-peptide \\
\end{tabular} & Rt12 RING-finger \\
\hline Signal-peptide; Transmembrane_regions & Methyltransferase domain \\
\hline EGGSHELL & 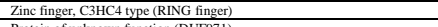 \\
\hline$\frac{\text { Signal-peptide }}{\text { Siginal-eptide }}$ & Protein of unknown function (DUF971) \\
\hline $\begin{array}{l}\text { Signal-ppptide } \\
\text { EGGSHELL:Signal-peptide; } \\
\end{array}$ & $\frac{\text { cw121 domain }}{\text { No }}$ \\
\hline Signal-peptide & Putative IRNA binding domain \\
\hline EGGSHELL:Signal-peptide; Transmembrane_regions & NUDIX domain \\
\hline \begin{tabular}{|l|l} 
Signal-peptide \\
\end{tabular} & 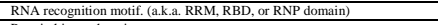 \\
\hline \begin{tabular}{|l} 
MTECHINOIDEA \\
IGBPP N 1 i Signal-pppide \\
\end{tabular} & \begin{tabular}{l|l} 
Protecin kinase domain \\
Metyltransfressedomin \\
\end{tabular} \\
\hline
\end{tabular}


International Journal of Computer Applications (0975 - 8887) Volume 81 - No.10, November 2013

\begin{tabular}{|c|c|}
\hline $\begin{array}{ll}\text { cre:_104804 } \\
\text { cre:_104846 }\end{array}$ & $\begin{array}{l}\frac{T}{\text { Tesmin/TSOl-like CXC domain }} \\
\text { ABCI family }\end{array}$ \\
\hline & 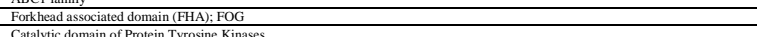 \\
\hline 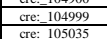 & 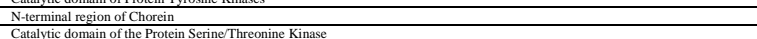 \\
\hline & 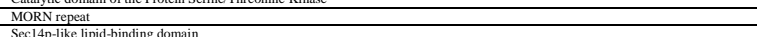 \\
\hline 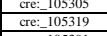 & 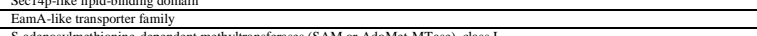 \\
\hline 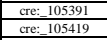 & $\begin{array}{l}\text { S-adenosylmethionine-dependent methyltransferases (SAM or AdoMct-MT ase, class L. } \\
\text { Hyypohtecical proctin; Provisional }\end{array}$ \\
\hline$\frac{5431}{4488}$ & 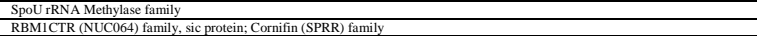 \\
\hline 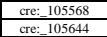 & 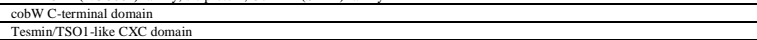 \\
\hline 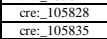 & 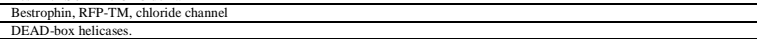 \\
\hline $\begin{array}{llll}\text { crec: } 105845 \\
\text { crev } 105873 \\
\end{array}$ & 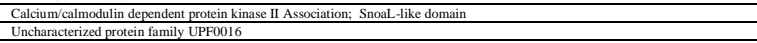 \\
\hline 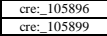 & $\begin{array}{l}\text { Macro domin } \\
\text { Zinc-inding domain of Paramyyoviridace } \mathrm{V} \text { protetin. }\end{array}$ \\
\hline 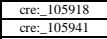 & $\begin{array}{l}\text { Catalytic domain of Protein Tyrosinc Kinases } \\
\text { Regulator of chromosome condensation (RCCl) repeat. }\end{array}$ \\
\hline 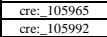 & 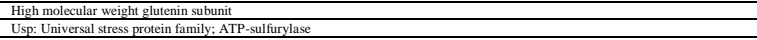 \\
\hline 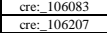 & 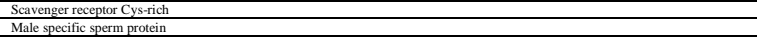 \\
\hline 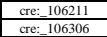 & Hyponthcical proctin \\
\hline \begin{tabular}{|ccccc} 
crect: 106339 \\
cre: 106402 \\
\end{tabular} & 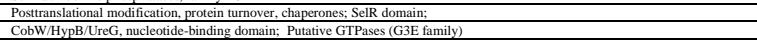 \\
\hline \begin{tabular}{|c|c|c|c|} 
cre: 106436 \\
cre: 1066461 \\
\end{tabular} & 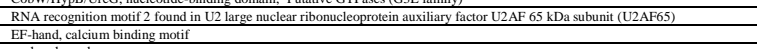 \\
\hline 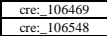 & 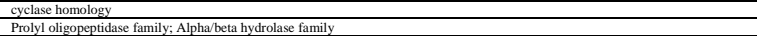 \\
\hline \begin{tabular}{|l|l|l} 
cre: 106555 \\
cre $: 106655$ \\
\end{tabular} & 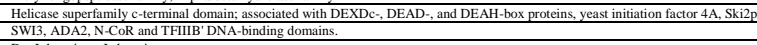 \\
\hline 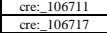 & 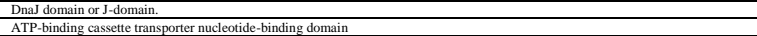 \\
\hline 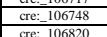 & 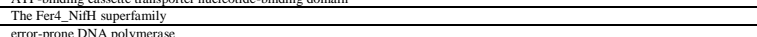 \\
\hline 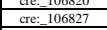 & 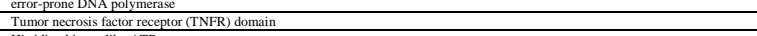 \\
\hline 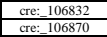 & Hisidine cinasac-like ATPases \\
\hline 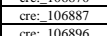 & 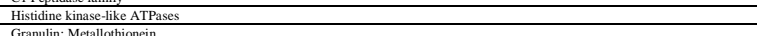 \\
\hline 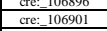 & Nongun: \\
\hline & 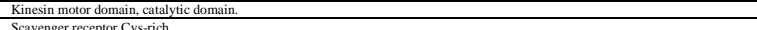 \\
\hline 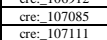 & 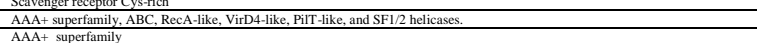 \\
\hline 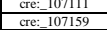 & 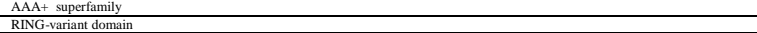 \\
\hline 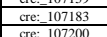 & 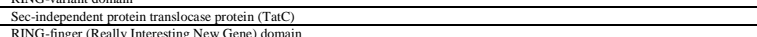 \\
\hline 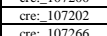 & 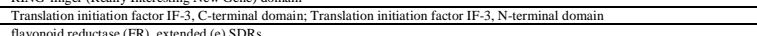 \\
\hline 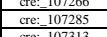 & 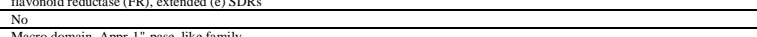 \\
\hline 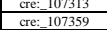 & 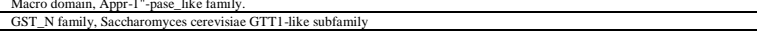 \\
\hline 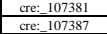 & 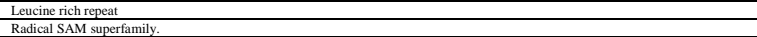 \\
\hline 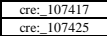 & 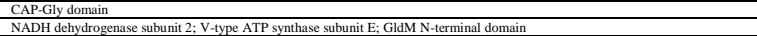 \\
\hline 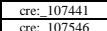 & 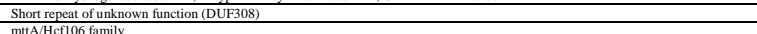 \\
\hline 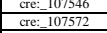 & 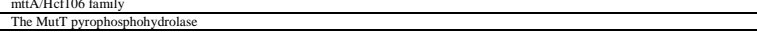 \\
\hline 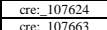 & HIT family \\
\hline 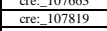 & 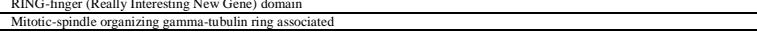 \\
\hline 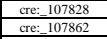 & $\begin{array}{ll}\text { Uncharacterized conserved protecin (DUF2358) } \\
\text { Aldo-kecto reductases ( } A K R \text { S }\end{array}$ \\
\hline 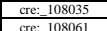 & 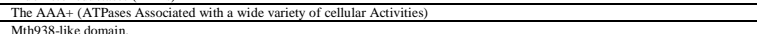 \\
\hline cre: 1088112 & 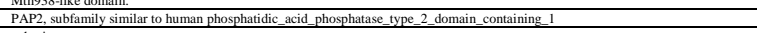 \\
\hline 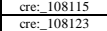 & $\begin{array}{l}\text { ankyrin repeats } \\
\text { 4Fec } 4 \text { single cluster domain }\end{array}$ \\
\hline 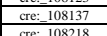 & 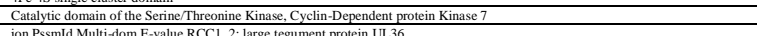 \\
\hline 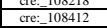 & 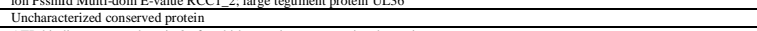 \\
\hline 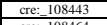 & ATP-binding cassecte domain 2 of multidutug resisitance-associated protein \\
\hline 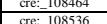 & 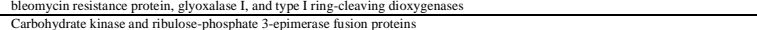 \\
\hline 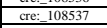 & SAssociated with a wide variety of cellularar Activities) \\
\hline 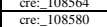 & 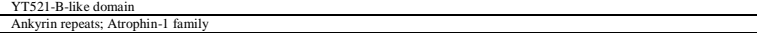 \\
\hline 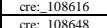 & 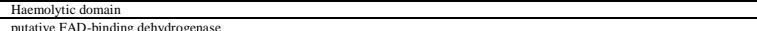 \\
\hline \begin{tabular}{|c|c|c|c|c|} 
cre: 108674 \\
\end{tabular} & 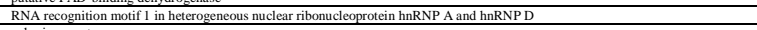 \\
\hline 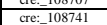 & \\
\hline 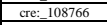 & \\
\hline 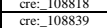 & 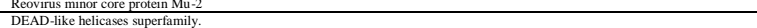 \\
\hline 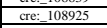 & onology domain \\
\hline 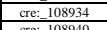 & 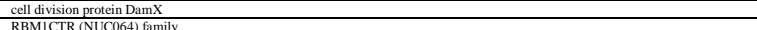 \\
\hline 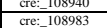 & 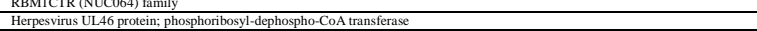 \\
\hline 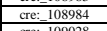 & 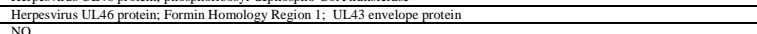 \\
\hline 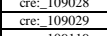 & 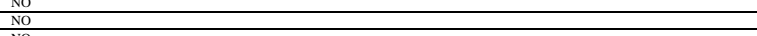 \\
\hline cre: -109119 & \\
\hline 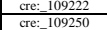 & $\begin{array}{l}\text { nerases III subunits gamma and tau } \\
\text { fffrase domin }\end{array}$ \\
\hline 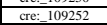 & protein L2424l/L24 \\
\hline 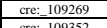 & Shelicase-primase complex component \\
\hline 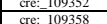 & $45 / 70 \mathrm{Kd}$ protein \\
\hline 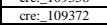 & solltransferaseses. \\
\hline 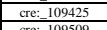 & Metallophosphatases superfamily, metallophosphatase domain; E4 protin \\
\hline 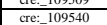 & 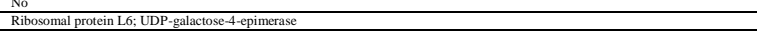 \\
\hline crev-109545 & Hisididine phosphatatase domain \\
\hline 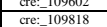 & 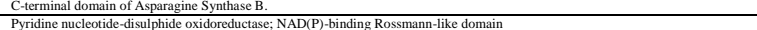 \\
\hline 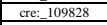 & Proctin of unknown function (DUF F 1055$)$ \\
\hline 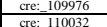 & 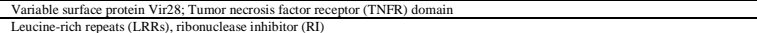 \\
\hline 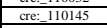 & 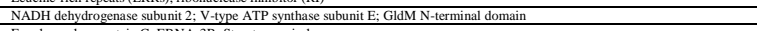 \\
\hline 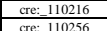 & Iycoprotein C; EBNA A-3B; Streptogramin Iyase \\
\hline 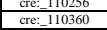 & $\begin{array}{l}\text { Extensinillike region } \\
\text { Clp amino terminal domain } \\
\end{array}$ \\
\hline 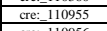 & Cystathionine beta-1yase family protein \\
\hline 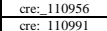 & \\
\hline 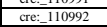 & \\
\hline 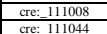 & 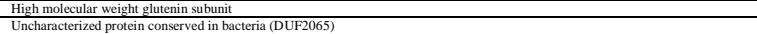 \\
\hline 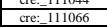 & 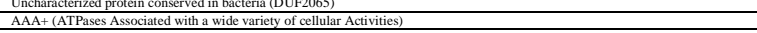 \\
\hline crev-1111068 & \\
\hline 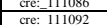 & 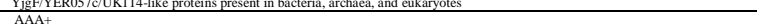 \\
\hline 运111122 & \\
\hline rel111160 & acid CoA synhictase $(L C \cdot F A C$ \\
\hline 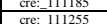 & phas sub \\
\hline & \\
\hline
\end{tabular}

\begin{tabular}{|c|c|}
\hline genal-peptide & $\begin{array}{l}\text { Tesmin/TSOl-like CXC domain, cysteine-rich domain } \\
\text { ABCI family }\end{array}$ \\
\hline Ismembranceregions & 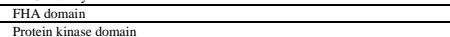 \\
\hline al-peptide & 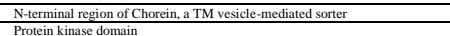 \\
\hline $\begin{array}{l}\text { ignal-peppide } \\
\text { NTGGRIN BETA: Signal-peptide }\end{array}$ & $\begin{array}{l}\text { MORN repati } \\
\text { CRALTRIOdomain }\end{array}$ \\
\hline 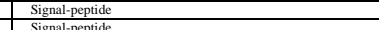 & 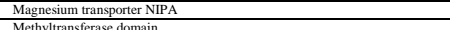 \\
\hline al-peppidice & 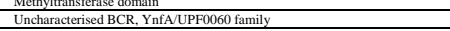 \\
\hline lippepinic & Spou rRNA Methylase family \\
\hline ignal-peptide & $\frac{\mathrm{No} o}{\text { Cobalamin synhthesis protein cobW C-terminal domain }}$ \\
\hline & 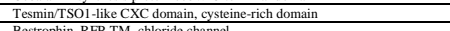 \\
\hline 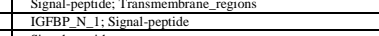 & 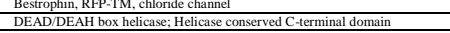 \\
\hline allpepent & 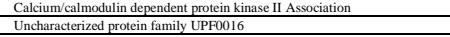 \\
\hline Enal-peptide; Transmmembrane_rcgions & \\
\hline TIEGRIN_BETA inasc: AGOUTLI: Sig & $\begin{array}{l}\text { No } \\
\text { ACT domain; : Protein } \text { yrosinc } k \\
\end{array}$ \\
\hline 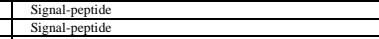 & \begin{tabular}{|l} 
Regulator of chromosome condensation $(R C C l)$ repeat \\
No
\end{tabular} \\
\hline$\overline{\overline{G S H E L L-S i g n a l-p e p h i d c}}$ & 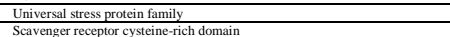 \\
\hline 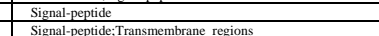 & 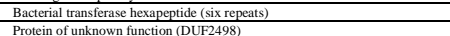 \\
\hline 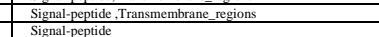 & \begin{tabular}{l|l} 
Protelin phosphatasce 2C \\
Sile domain \\
\end{tabular} \\
\hline nal-peptide & 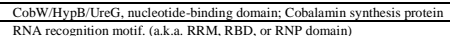 \\
\hline ignal-peptide & 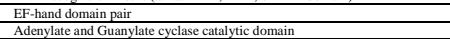 \\
\hline & 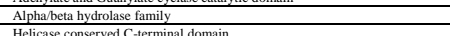 \\
\hline 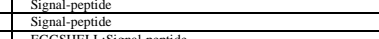 & $\begin{array}{l}\text { Helicase cosseredec C-terminal domain } \\
\text { Myb-like DNA-binding domain }\end{array}$ \\
\hline $\begin{array}{l}\text { GSHELLSignal-peppide } \\
\text { nal-peptide }\end{array}$ & \begin{tabular}{|l} 
D.and dominin \\
Muls domain V \\
\end{tabular} \\
\hline 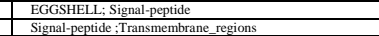 & 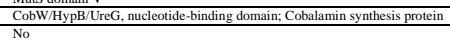 \\
\hline 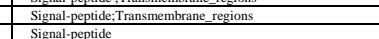 & $\frac{N_{0}}{\text { No }}$ \\
\hline 1-1.peptidice & 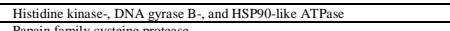 \\
\hline ganal-pephide & 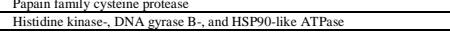 \\
\hline 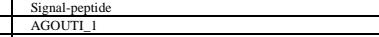 & $\begin{array}{ll}\text { No } \\
\text { No }\end{array}$ \\
\hline $\begin{array}{ll}\text { EGGSHELL } \\
\text { Signal-peptide }\end{array}$ & 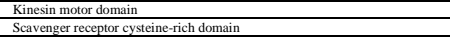 \\
\hline 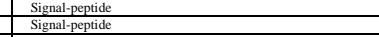 & 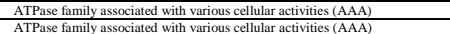 \\
\hline $\begin{array}{l}\text { sigalapppide } \\
\text { INTEGRIN_BETA:Signal-peppide }\end{array}$ & 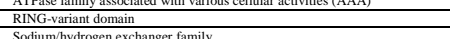 \\
\hline & 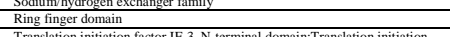 \\
\hline $\begin{array}{llll}\text { Signal-pepilde } \\
\text { Signal-peptide }\end{array}$ & 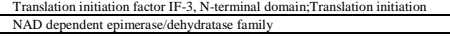 \\
\hline 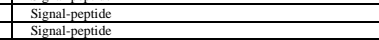 & $\begin{array}{l}\text { No } \\
\text { Macro domain } \\
\end{array}$ \\
\hline 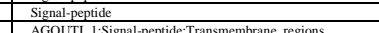 & 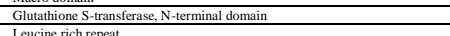 \\
\hline 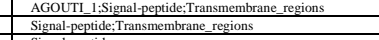 & $\begin{array}{l}\text { Lecuicin rich repeat } \\
\text { Ratical SAM superfamily } \\
\text { Ratal }\end{array}$ \\
\hline $\begin{array}{lll}\text { Signal-peptide } \\
\text { Signal-peptide }\end{array}$ & $\begin{array}{ll}\text { CAP-Gily domain } \\
\mathrm{No}\end{array}$ \\
\hline 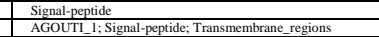 & 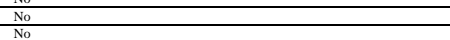 \\
\hline 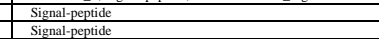 & $\begin{array}{ll}\text { No } \\
\text { NDIX domain } \\
\text { UIX }\end{array}$ \\
\hline 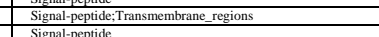 & 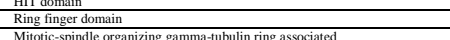 \\
\hline GSHELLLL:Signal-pepplide & 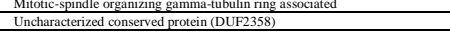 \\
\hline 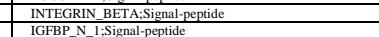 & 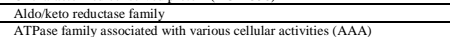 \\
\hline 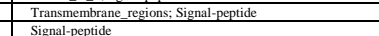 & 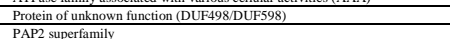 \\
\hline ant-pephide & 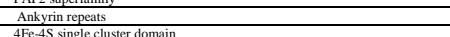 \\
\hline alatpeppidic; Transmembranc_cogions & 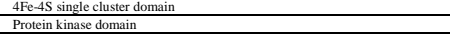 \\
\hline 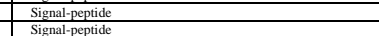 & 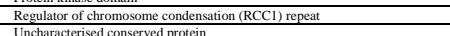 \\
\hline alleppopidid: Transmembrance_regions & 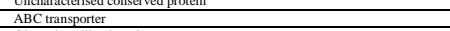 \\
\hline AcCXX.Siginal-pephide & 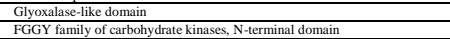 \\
\hline $\begin{array}{lll}\text { Enal-peptide } \\
\text { nnal-pentide }\end{array}$ & 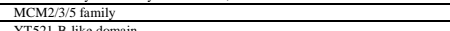 \\
\hline nenal-ppepide & $\begin{array}{l}\text { YTT22-1--like comain } \\
\text { Ankyrin repcats }\end{array}$ \\
\hline 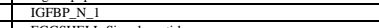 & \\
\hline 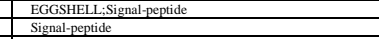 & 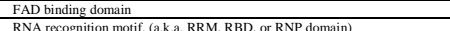 \\
\hline 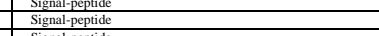 & 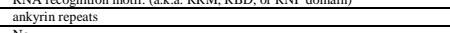 \\
\hline 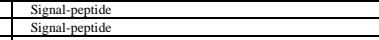 & $\begin{array}{ll}\text { No } \\
\text { NinU protin } \\
\end{array}$ \\
\hline 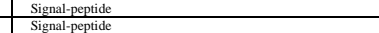 & tion system protc \\
\hline & IGuanylate cyclase catalalyic domain \\
\hline Signal-peptide: Transmembranc_cregions & \\
\hline all-peppice & \\
\hline $\begin{array}{l}\text { MTECHINOIDEA; Signal-pephide } \\
\text { Mite }\end{array}$ & $\frac{\mathrm{No}}{\mathrm{No}}$ \\
\hline $\begin{array}{l}\text { Signal-peptidi; Transmemblraner_egions } \\
\text { Signal-peptide: Transmmembranc regions }\end{array}$ & $\frac{\text { No }}{\text { No }}$ \\
\hline 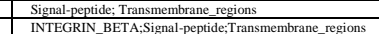 & 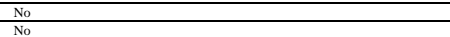 \\
\hline $\begin{array}{ll}\text { No } \\
\text { Somplal-pentide }\end{array}$ & $\begin{array}{l}\text { No } \\
\text { Mechyltrans ferase domain } \\
\end{array}$ \\
\hline 1-1.peppidice & $\begin{array}{l}\text { Ribosomal protein L24e } \\
\text { No }\end{array}$ \\
\hline 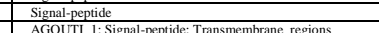 & $=$ \\
\hline 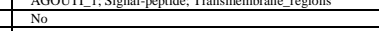 & Crases group 1 \\
\hline 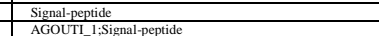 & \\
\hline Wrentide & No \\
\hline al-pepentice & 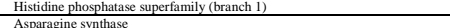 \\
\hline 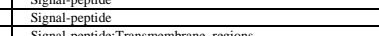 & 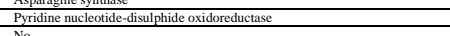 \\
\hline 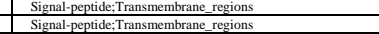 & No \\
\hline 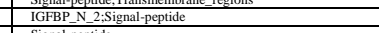 & Leucine rich repeat \\
\hline 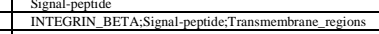 & 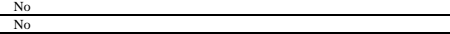 \\
\hline Signal-peptide: Transmembrane_regions & $\frac{\mathrm{No} \text { o }}{\mathrm{C} \text { Comino terminal domin }}$ \\
\hline 1-peptide & 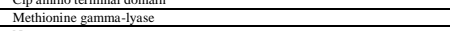 \\
\hline $\begin{array}{l}\text { Signal-pepidec } \\
\text { MTMLLLSC:Signal-peppide: Transmembrance regions }\end{array}$ & $\frac{\mathrm{No}}{\mathrm{No}}$ \\
\hline Signal-pepidid: Transmementbancercregions & $\overline{0}$ \\
\hline $\begin{array}{l}\text { Signa-1-peptide } \\
\text { Signal-ppride }\end{array}$ & \\
\hline reppice & nal-54 interaction domain: Bacterial regulatory protein, Fis family \\
\hline $\begin{array}{l}\text { Signal-peptide } \\
\end{array}$ & \\
\hline al-peptide & 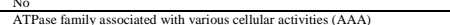 \\
\hline al-peptide & ation factor Tu GiTP binding domain \\
\hline 型 & (1) \\
\hline & 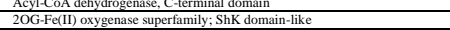 \\
\hline & 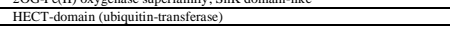 \\
\hline
\end{tabular}


International Journal of Computer Applications (0975 - 8887) Volume 81-No.10, November 2013

\begin{tabular}{|c|c|}
\hline 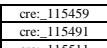 & 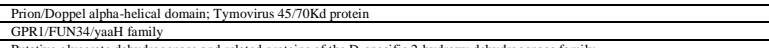 \\
\hline 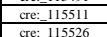 & 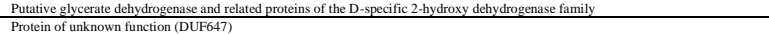 \\
\hline & No \\
\hline & 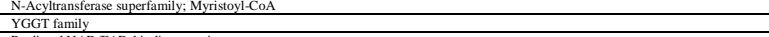 \\
\hline 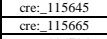 & 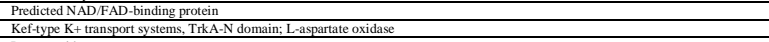 \\
\hline 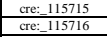 & 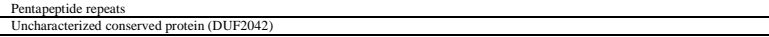 \\
\hline 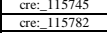 & 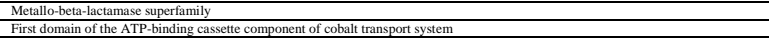 \\
\hline 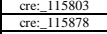 & 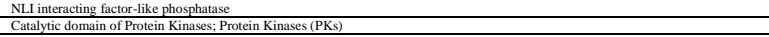 \\
\hline 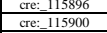 & 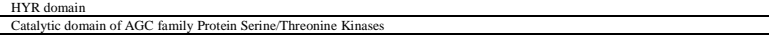 \\
\hline 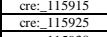 & $\begin{array}{ll}\text { WD40 domain } \\
\text { AAA domain } \\
\end{array}$ \\
\hline 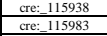 & 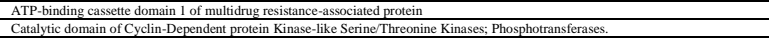 \\
\hline 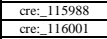 & 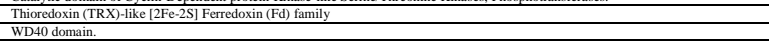 \\
\hline 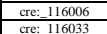 & 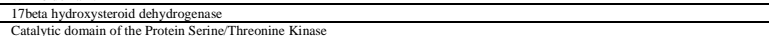 \\
\hline 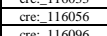 & 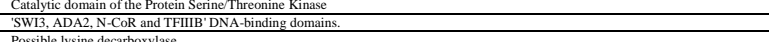 \\
\hline & 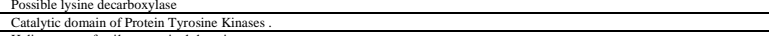 \\
\hline 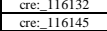 & 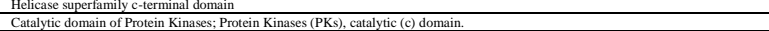 \\
\hline & 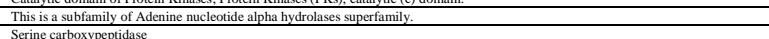 \\
\hline 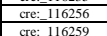 & 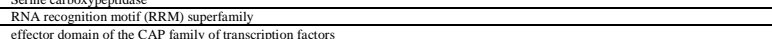 \\
\hline & $\begin{array}{l}\text { DEAD-ike chelicaceses superfamily. } \\
\text { D. }\end{array}$ \\
\hline & 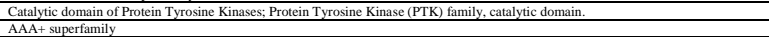 \\
\hline 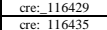 & 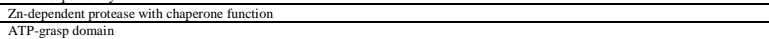 \\
\hline & 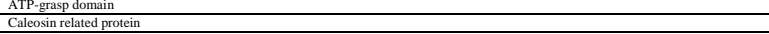 \\
\hline & 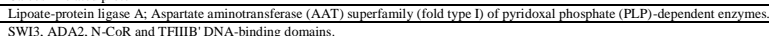 \\
\hline 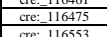 & 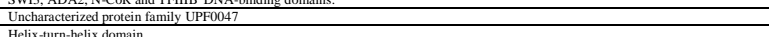 \\
\hline 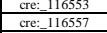 & $\begin{array}{l}\text { Hecix turnthelil domain } \\
\text { AAA+ Superfimily }\end{array}$ \\
\hline 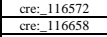 & 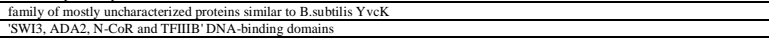 \\
\hline & $\begin{array}{l}\text { Protein of unknown function (DUV760) } \\
\text { DEAD-like helicicacs superfaumily. }\end{array}$ \\
\hline 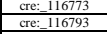 & 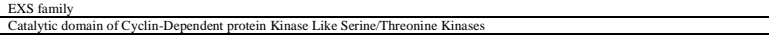 \\
\hline & 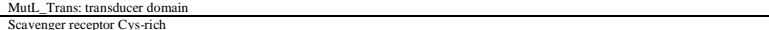 \\
\hline & 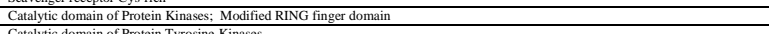 \\
\hline 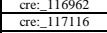 & 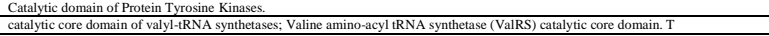 \\
\hline 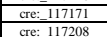 & 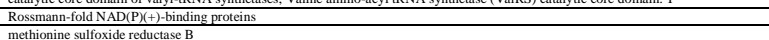 \\
\hline 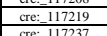 & 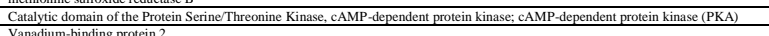 \\
\hline 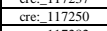 & 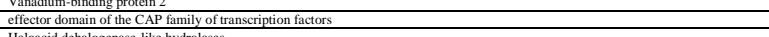 \\
\hline 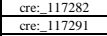 & 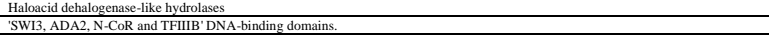 \\
\hline & $\begin{array}{l}\text { Helicase superfamily c-terminal domain } \\
\text { alphahbeta hydrolase fold }\end{array}$ \\
\hline 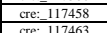 & 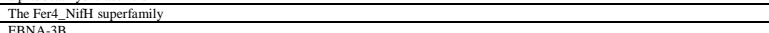 \\
\hline 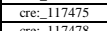 & 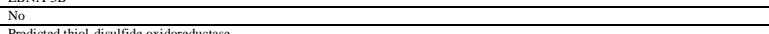 \\
\hline 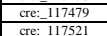 & 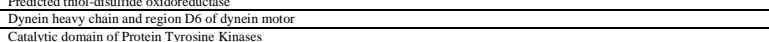 \\
\hline & \\
\hline 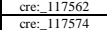 & 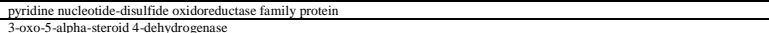 \\
\hline 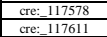 & 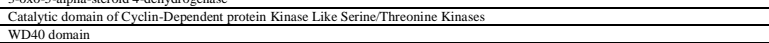 \\
\hline 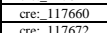 & 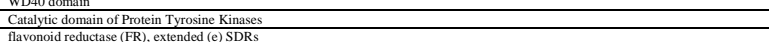 \\
\hline 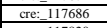 & 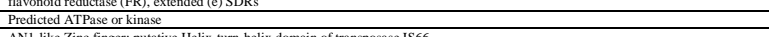 \\
\hline creve 1172820 & 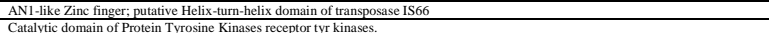 \\
\hline & 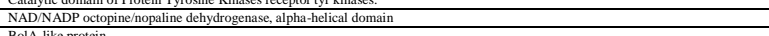 \\
\hline 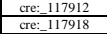 & 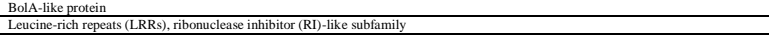 \\
\hline 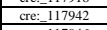 & Uncharacteterized protein family UPF0047 \\
\hline 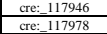 & 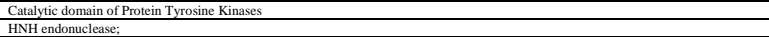 \\
\hline \begin{tabular}{|ccccc} 
crec. 117999 \\
crev 118003 \\
\end{tabular} & 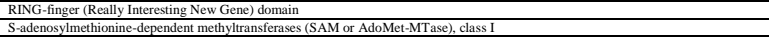 \\
\hline 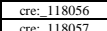 & PGAPl-like protin \\
\hline 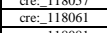 & 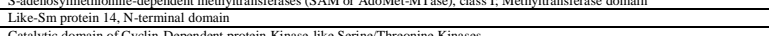 \\
\hline 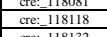 & 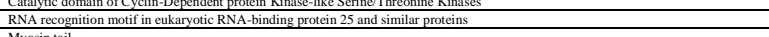 \\
\hline 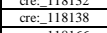 & 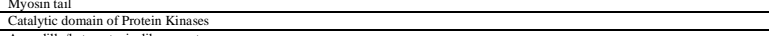 \\
\hline crec:-118166 & 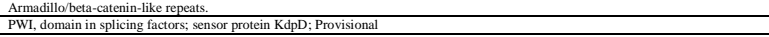 \\
\hline 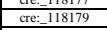 & 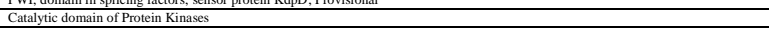 \\
\hline 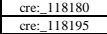 & 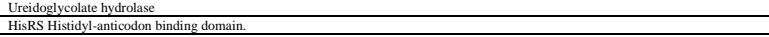 \\
\hline 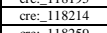 & $\begin{array}{l}\text { Metal dependent phosphohydrolases with conserved HD' motif } \\
\text { Prin }\end{array}$ \\
\hline 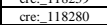 & phohydrolases with conserved 'HD' motif \\
\hline 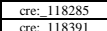 & 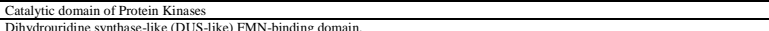 \\
\hline 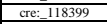 & innction (DUF4346) \\
\hline 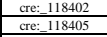 & 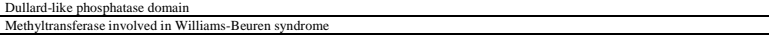 \\
\hline & 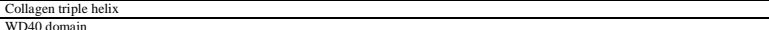 \\
\hline 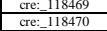 & $\begin{array}{lll}\text { WD40 do } \\
\text { AAAdor }\end{array}$ \\
\hline 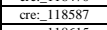 & e(QOR) \\
\hline creve-11 & 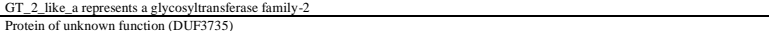 \\
\hline 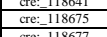 & 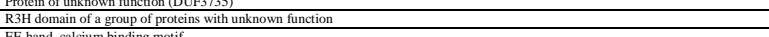 \\
\hline cre: 11 11 & tion (DUF3411) \\
\hline & modtutaror 3 f family/CDC50 family \\
\hline & $\begin{array}{l}\text { modulator } 3 \text { t tamily } / \mathrm{CDC} 50 \text { tamily } \\
\text { minal domain }\end{array}$ \\
\hline crev-118928 & 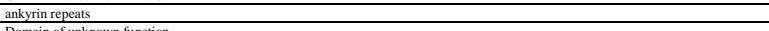 \\
\hline 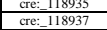 & 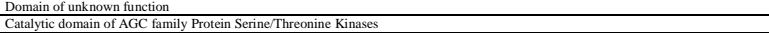 \\
\hline 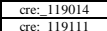 & 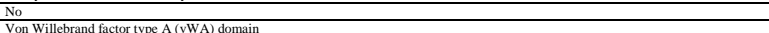 \\
\hline 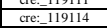 & 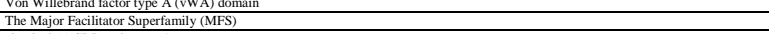 \\
\hline 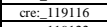 & 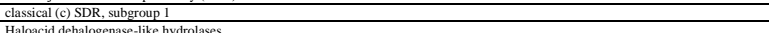 \\
\hline $\begin{array}{l}\text { cre:-: } 119122 \\
\text { cre:_119140 }\end{array}$ & 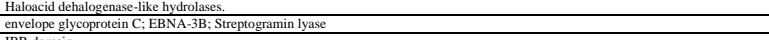 \\
\hline & \\
\hline 198 & ITFIIII' DNA-binding domains. \\
\hline & ger, Lish dimerisation motif \\
\hline & \\
\hline
\end{tabular}

\begin{tabular}{|c|c|}
\hline $\begin{array}{c}\text { GGSHELL: Signal-pephide } \\
\text { Vo }\end{array}$ & 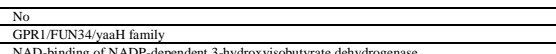 \\
\hline & 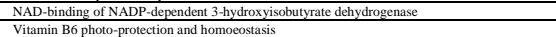 \\
\hline 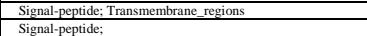 & $\begin{array}{ll}\text { No } \\
\text { cetylyansfererse (GNAT) domain }\end{array}$ \\
\hline 1.t-peppide & 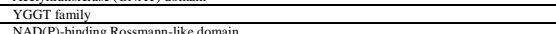 \\
\hline 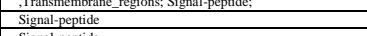 & 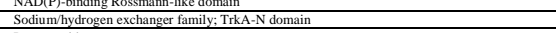 \\
\hline all-peptide & 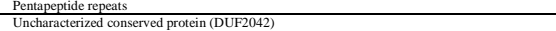 \\
\hline $\begin{array}{l}\text { ignal-pephide } \\
\text { GSGSELLS. Sigal-pepide }\end{array}$ & 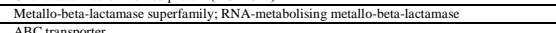 \\
\hline & 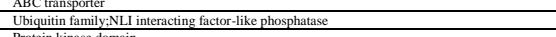 \\
\hline & $\begin{array}{l}\text { Protcin Kinase domain } \\
\text { HYX domain }\end{array}$ \\
\hline 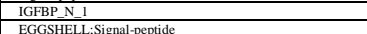 & 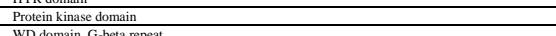 \\
\hline 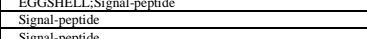 & $\begin{array}{l}\text { WD domain G- Getat repeat } \\
\text { AAA domain }\end{array}$ \\
\hline & 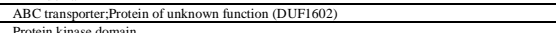 \\
\hline 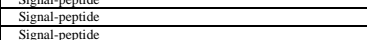 & $\begin{array}{ll}\text { No } \\
\text { Wo dominin.G-betar receat }\end{array}$ \\
\hline & 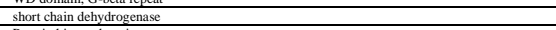 \\
\hline 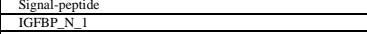 & $\begin{array}{l}\text { Protcie Kinase comain } \\
\text { Myb-like DNA-binding domain } \\
\end{array}$ \\
\hline $\begin{array}{l}\text { gnal-peptide:Transmembrancercegions } \\
\end{array}$ & $\begin{array}{l}\text { Possible lysinind dcarboxlysase } \\
\text { Posible yysine decarboxylase }\end{array}$ \\
\hline I-1.peptide & $\begin{array}{l}\text { Helicase conserved C-terminal domain } \\
\text { Protoin Kinas domain }\end{array}$ \\
\hline Inenide & $\begin{array}{ll}\text { ATP-binding region } \\
\end{array}$ \\
\hline 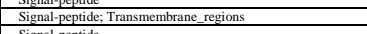 & 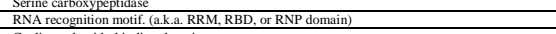 \\
\hline & 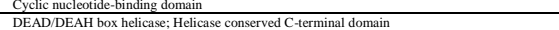 \\
\hline $\begin{array}{lll}\text { Enal-peppide } \\
\text { ACTX }\end{array}$ & 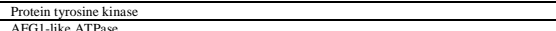 \\
\hline nal-peppide & Pepidiase family M48 \\
\hline ignal-peptide NTE: Sinnal-peptide & 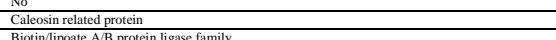 \\
\hline thalpeptide & 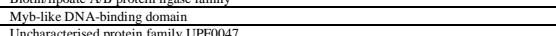 \\
\hline 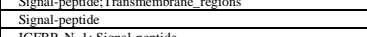 & 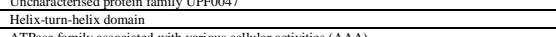 \\
\hline $\begin{array}{l}\text { IGFBP_N_1; Signal-peppide } \\
\text { Signal-peptide; Transmembrane_regions }\end{array}$ & 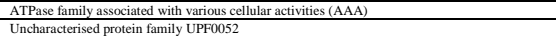 \\
\hline all-peptide & Myb-like DNA-binding domain \\
\hline ignal-peptide & 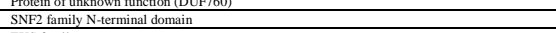 \\
\hline 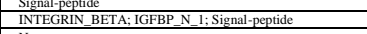 & $\begin{array}{l}\text { EXS family } \\
\text { Protein kinase domain } \\
\end{array}$ \\
\hline 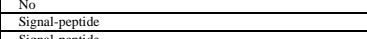 & 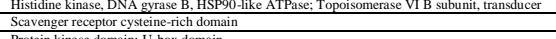 \\
\hline & 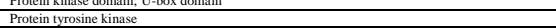 \\
\hline pepplide & 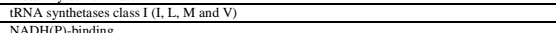 \\
\hline nalal-peptide & $\begin{array}{l}\text { NoDHH (P)-binding } \\
\text { SelR doman }\end{array}$ \\
\hline al-peppide & $\begin{array}{ll}\text { Proltein kinase domain } \\
\text { No }\end{array}$ \\
\hline 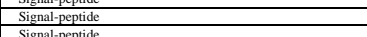 & 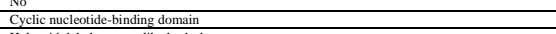 \\
\hline 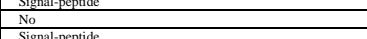 & 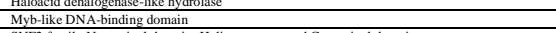 \\
\hline 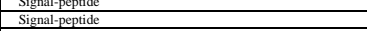 & 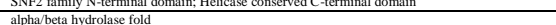 \\
\hline al-peptide & 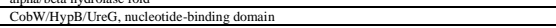 \\
\hline al-peptide & \\
\hline 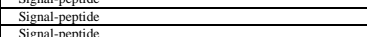 & Protein of unknown function, DUF393 \\
\hline igal-pephide & 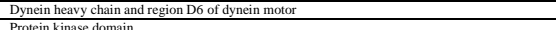 \\
\hline 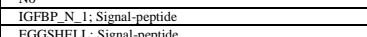 & 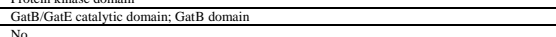 \\
\hline 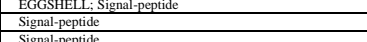 & $\begin{array}{ll}\text { No } \\
\text { No } \\
\text { Protin kinasc doming }\end{array}$ \\
\hline 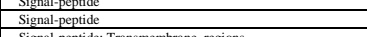 & 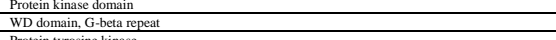 \\
\hline 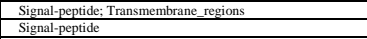 & 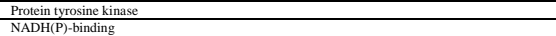 \\
\hline $\begin{array}{l}\text { Signal-pephide } \\
\text { SINERIN_EETA }\end{array}$ & $\begin{array}{l}\text { Uncharacterisec P-loop hydrolase UPF0079 } \\
\text { ANl-like Zinc finger }\end{array}$ \\
\hline 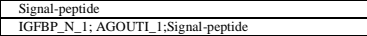 & 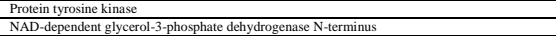 \\
\hline 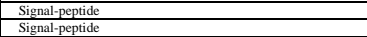 & $\begin{array}{ll}\text { No } \\
\text { Lencine rich repeat; }\end{array}$ \\
\hline $\begin{array}{llll}\text { No } \\
\text { Signal-peptide }\end{array}$ & 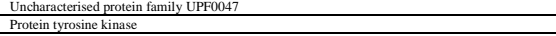 \\
\hline $\begin{array}{ll}\text { No } \\
\text { Signal-peptide }\end{array}$ & $\begin{array}{l}\text { No } \\
\text { Ring finger domain }\end{array}$ \\
\hline & 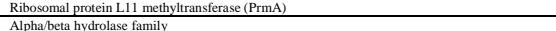 \\
\hline 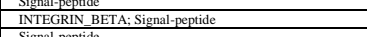 & 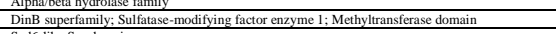 \\
\hline 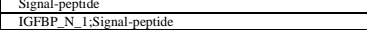 & $\begin{array}{l}\frac{S c d d-\text {-lik Sm domain }}{\text { Protelin kinase domain }} \\
\end{array}$ \\
\hline 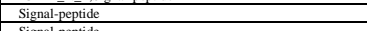 & 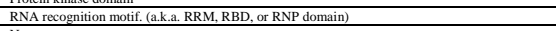 \\
\hline 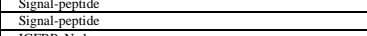 & $\begin{array}{ll}\text { Noo } \\
\text { Protcin kinase domain }\end{array}$ \\
\hline 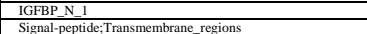 & 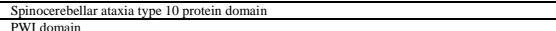 \\
\hline 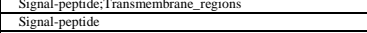 & $\begin{array}{l}\text { PII domain } \\
\text { Proten kinase domain } \\
\end{array}$ \\
\hline 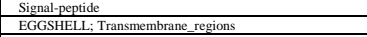 & Anicodon binding domain \\
\hline 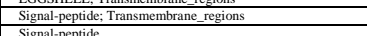 & $35^{5}$-cyclic nucleotide phosphodiesterase \\
\hline $\begin{array}{l}\text { Signal-1peptide Transmembranc_regions } \\
\text { Signal-peptide:Trasme }\end{array}$ & $\begin{array}{l}\text { Pirin } \\
3^{\prime} 5^{\prime} \text {-yclic nucleotide phosphodiesterase }\end{array}$ \\
\hline Signal-peppidice & 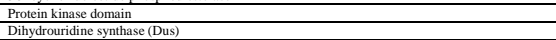 \\
\hline al-peper & 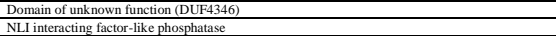 \\
\hline 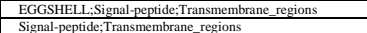 & 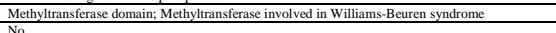 \\
\hline 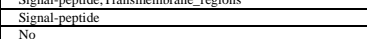 & $\frac{\text { No o domain, G-becta repecat }}{\text { WD }}$ \\
\hline Signal-peppide & $\begin{array}{l}\text { AAAdomann } \\
\text { Alcholol dehydrogenase GroES-like domain: Zinc-binding dechydrogenase }\end{array}$ \\
\hline 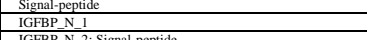 & 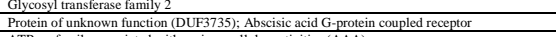 \\
\hline 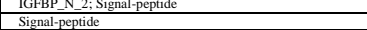 & 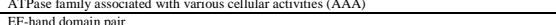 \\
\hline 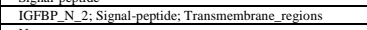 & Domain of unknown function (DUF3411) \\
\hline Signal-peptide & 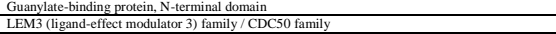 \\
\hline nal-pephide & $\begin{array}{ll}\text { GHMP kinases } \mathrm{N} \text { terminal domain } \\
\mathrm{N} O \mathrm{O}\end{array}$ \\
\hline 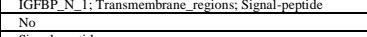 & of unknown function (DUF4205) \\
\hline al-peptide & $\begin{array}{ll}\text { Proteli kinase domain } \\
\end{array}$ \\
\hline 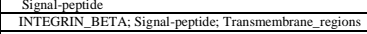 & $\begin{array}{lll}\text { No } \\
\text { Copine }\end{array}$ \\
\hline $\begin{array}{l}\text { Signal-peptide; Transmembrane_regions } \\
\text { Sigigal-peptide }\end{array}$ & Majior Facilitator Superfamily \\
\hline 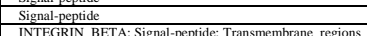 & $\begin{array}{l}\text { Haloacid dehalogengase-like hydrolase } \\
\text { lose }\end{array}$ \\
\hline & IBR domain \\
\hline $\begin{array}{l}\text { Myb-like DNA-binding domain } \\
\text { FGGSHEL- }\end{array}$ & Protein of unknown function (DUF 1264) \\
\hline 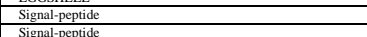 & 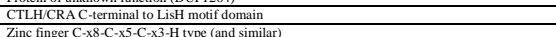 \\
\hline \begin{tabular}{|l|l|l} 
Sigal-ppepide \\
Signal-pepiide \\
\end{tabular} & 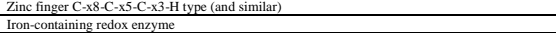 \\
\hline
\end{tabular}




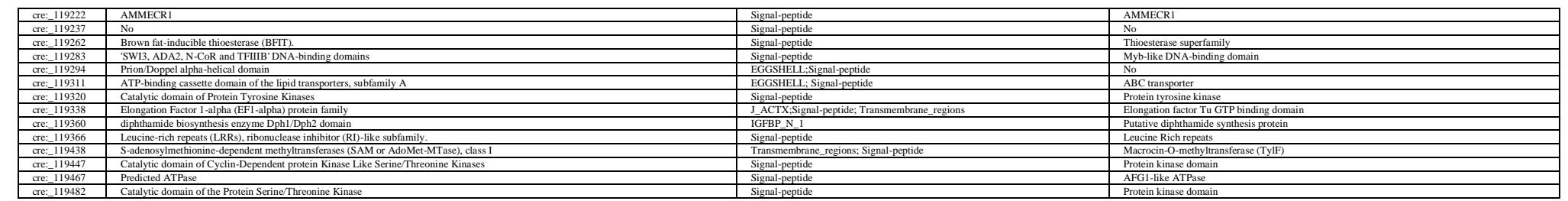

\section{CONCLUSION}

Authors have applied genomics approach to recommend the potential functions for hypothetical proteins of Chlamydomonas reinhardtii. The prediction of functions of proteins can be analyzed by using accurate annotations. Thus, the functions of proteins can help in better knowing about various regulatory mechanisms that interact to yield a final output from the system. Current study can offer activities associated with nitrogen fixation, acid biosynthesis, $\mathrm{CO}_{2}$ fixation, ATP formation, electron transport reactions, photosynthesis function, identified proteins crucial for the harvesting and use of excitation energy.

\section{REFERANCES}

[1] Boesger, J., Wagner, V., Weisheit, W., Mittag, M. 2009. Analysis of Flagellar Phosphoproteins from Chlamydomonas reinhardtii. Eukaryotic cell. 8(7), 922932.

[2] Harris, E. 2001. Chlamydomonas as a model organism. Annu Rev Plant Physiol Plant Mol Biol. 52, 363-406.

[3] Rochaix, J., 1995. Chlamydomonas reinhardtii as the photosynthetic yeast. Annu. Rev. Genet. 29, 209-230.

[4] Merchant, S., Prochnik, S., Vallon, O., Harris, E., Karpowicz, S., Witman, G., et al. 2007. The Chlamydomonas genome reveals the evolution of key animal and plant functions. Science 318, 245-250.

[5] Li, J., 2004. Cell. 117, 541.

[6] Storms, R., Hastings, P. 1977. Exp Cell Res. 104, 39

[7] Merchant, S., Allen, M, Kropat, J., Moseley, J., Long, J., Tottey, S., Terauchi, A., 2006. Between a rock and a hard place: trace element nutrition in Chlamydomonas. Biochim Biophys Acta 1763, 578-594.

[8] Grossman, A. R., Karpowicz, S. J., Heinnickel, M., Dewez, D., Hamel, B., Dent, R., Niyogi, K. K., Johnson, X., Alric, J., Wollman, F. A., Li, H., Merchant, S. S. 2010. Phylogenomic analysis of the Chlamydomonas genome unmasks proteins potentially involved in photosynthetic function and regulation. Photosynth Res. $106,3-17$.

[9] Gore, D. 2009. In silico Prediction of Structure and Enzymatic Activity for Hypothetical Proteins of Shigella flexneri. Biofrontiers. 1(2), 1-10.

[10] Edward, E., Gary, L. G., Osnat, H., John, M., John, O., Roberto, J. P., Linda, B., Delwood, R., Andrew, J. H. 2000. Biological function made crystal clear- annotation of hypothetical proteins via structural genomics. Current Opinion in Biotechnology. 11, 25-30.

[11] Choi, E. J., Bae, S. M., Ahn, W. S. 2008. Antiproliferative effects of quercetin through cell cycle arrest and apoptosis in human breast cancer MDA-MB453 cells. Arch Pharm Res.

[12] Altschul, S. F., Madden, T. L., Schaffer, A. A., Zhang, J., Zhang, Z., Miller, W., Lipman, D.J. 1997. Gapped BLAST and PSI-BLAST: "a new generation of protein database search programs". Nucleic Acids Res. 25 (17), $3389-402$.

[13] Schaffer, A. A., Aravind, L., Madden, T. L., Shavirin, S., Spouge, J. L., Wolf, Y. I., Koonin, E. V., Altschul, S. F. 2001. Improving the accuracy of PSI-BLAST protein database searches with composition-based statistics and other refinements. Nucleic Acids Res. 29(14), 2994 3005 .

[14] Aron, M., Bauer, John, B. A., Myra, K, D., Carol, D. S., Noreen, R. G., Marc, G., Luning, H., Siqian, H., David, I. H., John, D.J., Zhaoxi, K., Dmitri, K., Christopher, J. L., Cynthia, A. L., Chunlei, L., Fu, L., Shennan, L., Gabriele, H. M., Mikhail, M., James, S. S., Narmada, T., Roxanne, A. Y., Jodie, J. Y., Dachuan, Z., Stephen, H. B. 2006. CDD: "a conserved domain database for interactive domain family analysis. "Nucleic Acids Research. 35, 237-240.

[15] Marchler-Bauer, A. 2011. Nucleic Acids Res. 39, 225.

[16] Zdobnov, E. M., Rolf, A. 2001. Interproscan- an integration platform for the signatures recognition methods in InterPro. Bioinformatics .17, 847-848.

[17] Alex, B., Lachlan, C., Richard, D., Robert, D. F., Volker, H., Sam, G. J., Ajay, K., Mhairi, M., Simon, M., Erik, L. L. S., David, J. S., Corin, Y., Sean, R. E. 2004. The Pfam families' database. Nucleic Acids Research. 32, 138-141.

[18] Finn, R. D. 2010. Nucleic Acids Res. 38, 211.

[19]Grossman, A. R., Steven, J., Karpowicz, M., Heinnickel, D., Dewez, B., Hamel, R., Dent, T., Niyogi, K. K. 2010. Phylogenomic analysis of the Chlamydomonas genome unmasks proteins potentially involved in photosynthetic function and regulation. Photosynthesis research 106, 317.

[20] Misra, N., Panda P. K., Parida B. K., Mishra B. K. 2012. Phylogenomic Study of Lipid Genes Involved in Microalgal Biofuel Production-Candidate Gene Mining and Metabolic Pathway Analyses. Evolutionary bioinformatics online 8, 545 . 